\title{
ERRATUM
}

doi:10.1038/nature05299

\section{Centrosome polarization delivers secretory granules to the immunological synapse}

Jane C. Stinchcombe, Endre Majorovits, Giovanna Bossi, Stephen Fuller \& Gillian M. Griffiths

Nature 443, 462-465 (2006)

In the print and PDF versions of this Letter, Figure 2 was printed incorrectly. Panels $\mathrm{d}$ and $\mathrm{h}$ were missing and part of panels $\mathrm{c}$ and $\mathrm{g}$ were removed. The online HTML version is correct. Figure 2 is reprinted correctly below.

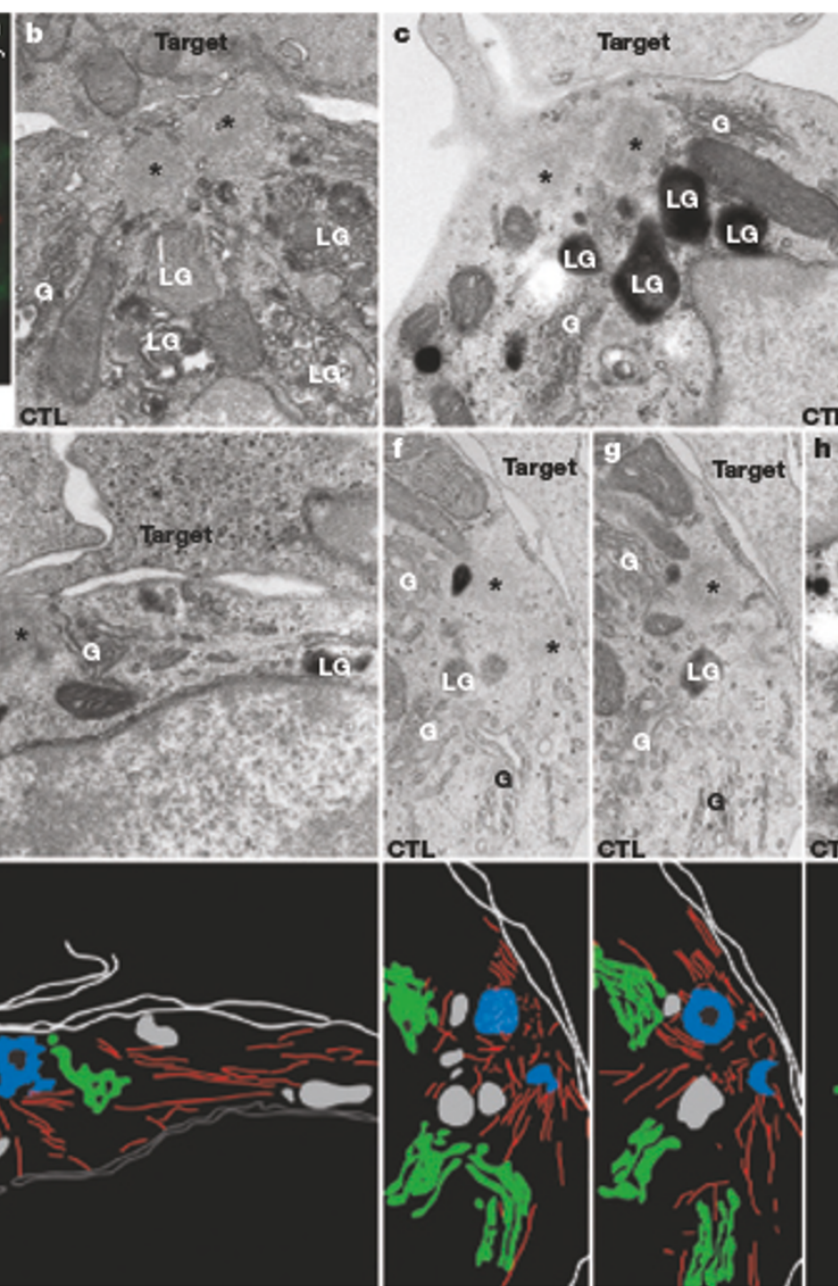
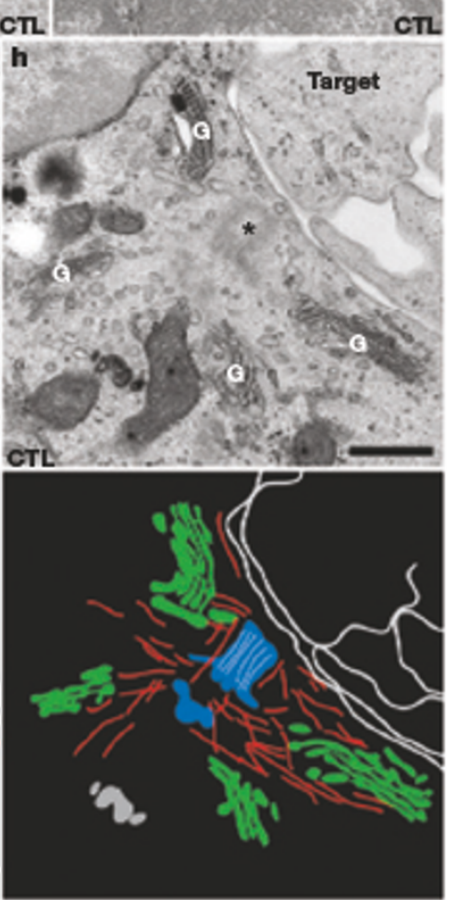